\title{
High diversity of chickpea Mesorhizobium species isolated in a
}

Portuguese agricultural region

\section{Serviços $9^{\circ}$ on \\ $\mathrm{NCBI}$}

\author{
Print E-mail Add to Marked List Save to EndNote Web \\ Save to EndNote, RefMan, ProCite more options
}

Author(s): Laranjo M, Machado J, Young JPW, Oliveira S

Source: FEMS MICROBIOLOGY ECOLOGY Volume: 48 Issue: 1 Pages: 101-107 Published: APR 12004

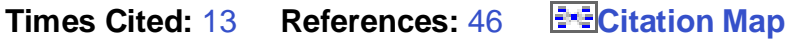

Abstract: Chickpea rhizobia isolated from Portuguese soils were assigned to the genus Mesorhizobium by 16S-rDNA sequencing. High species diversity was found within populations of an agricultural region in the south of Portugal.;Besides the expected Mesorhizobium ciceri and M. mediterraneum, some isolates were close to $\mathrm{M}$. loti or $\mathrm{M}$. tianshanense and some formed a clade that may represent a new species. A new PCR-based approach, named direct amplified polymorphic DNA (DAPD) analysis, supported the 16Sbased phylogeny. This suggests that this method could be used as a molecular tool to assess genetic relationships. Evaluation of genetic diversity by 16S-rDNA sequence, DAPD and protein profiles showed different levels of heterogeneity in natural populations. 2004 Federation of European Microbiological Societies. Published by Elsevier B.V. All rights reserved.

Document Type: Article

Language: English

Author Keywords: Mesorhizobium; 16S-rDNA; DAPD; chickpea; diversity; microbial

KeyWords Plus: CICER-ARIETINUM-L; POLYMERASE-CHAIN-REACTION; SP-NOV; GENETIC DIVERSITY; RHIZOBIUM-MEDITERRANEUM; RNA GENE; STRAINS; SOILS; LOTI; TIANSHANENSE

Reprint Address: Oliveira, S (reprint author), Univ Evora, ICAM, Lab Microbiol Solo, Evora, Portugal

\section{Addresses:}

1. Univ Evora, ICAM, Lab Microbiol Solo, Evora, Portugal

2. Univ Evora, Dept Biol, P-7002554 Evora, Portugal

3. Inst Nacl Saude Dr Ricardo Jorge, Bacteriol Lab, Lisbon, Portugal

4. Univ York, Dept Biol, York YO10 5DD, N Yorkshire England

E-mail Addresses: ismo@uevora.pt

Publisher: ELSEVIER SCIENCE BV, PO BOX 211, 1000 AE AMSTERDAM, NETHERLANDS 